\title{
How to break into a microcosm: localization of hidden hosts by fig wasp parasitoids
}

\author{
Pratibha Yadav ${ }^{1,2}$, Anusha L. K. Kumble', Mahua Ghara ${ }^{1}$, \\ Jean-Marie Bessière ${ }^{3}$ and Renee M. Borges ${ }^{1, *}$ \\ ${ }^{1}$ Centre for Ecological Sciences, Indian Institute of Science, Bengaluru 560 012, India \\ ${ }^{2}$ LIVIN Farms Agrifood GmbH, Vienna 1110, Austria \\ ${ }^{3}$ École Nationale Supérieure de Chimie, 240 Avenue du Professeur Emile Jeanbrau, 34090 Montpellier, France
}

\begin{abstract}
Host-finding behaviour and decision-making in a tritrophic interaction are often complex, especially when hosts are hidden within plant or animal tissues. We study how parasitoid fig wasps assess fig hosts for oviposition. These wasps oviposit into fig inflorescences (syconia) in which conspecifics have previously deposited eggs, possibly to avoid sib-mating for offspring that will develop and mate within these enclosed inflorescences. The syconia previously visited by conspecifics can be identified from species-specific chemical footprints left on the outer syconium surface, and these are chemically characterized. The tarsal morphology that may facilitate such identification is also described. Fig wasps have a haplodiploid breeding system in which males are haploid, developing from unfertilized eggs, and are much smaller in size than females. We therefore also experimentally determined that these parasitoids do not deposit fertilized eggs destined to become females on male hosts, a behaviour likely driven by the greater nutritional requirements of female offspring compared to the smaller-sized males. We also quantified carbon dioxide $\left(\mathrm{CO}_{2}\right)$ production from galls of different species, as speciesspecific hosts within the syconia are likely identified by differential $\mathrm{CO}_{2}$ production from galls, whose levels are assessed via the sensilla present on the parasitoid ovipositor.
\end{abstract}

Keywords: Chemical footprints, fig wasps, hidden hosts, oviposition, parasitoids, synconia.

PARASITOIDS are of great interest for their ability to provide functional and evolutionary insights into host location by insects during oviposition ${ }^{1-3}$. When searching for hosts hidden within plants, these predators face the reliability-detectability problem ${ }^{4}$ and therefore must optimize their search strategy for efficient host exploitation which may involve decisions based on host size and accessibility $^{5,6}$. We study host location strategy and associated oviposition tools in a fig wasp parasitoid (Pteromalidae) within the common cluster fig Ficus racemosa. Unlike pollinator wasps, fig wasp parasitoids do not enter the

*For correspondence. (e-mail: renee@iisc.ac.in) enclosed globular fig inflorescence (syconium), but gain access to their hidden hosts (larvae of other fig wasps) by ovipositing from the exterior (Figure 1).

While parasitoids often exploit the footprints of previously ovipositing hosts to detect hidden host larvae ${ }^{7,8}$, presence of ovipositing conspecifics may also indicate the suitability of the host as has been observed across several insect taxa, including hymenopterans like diprionid sawflies and Drosophila parasitoids ${ }^{9}$. In this study, our focal parasitoid (Apocrypta sp. 2) oviposits in the absence of conspecifics, but can also form aggregations on syconia for oviposition (Figure 1). Such ovipositing aggregations may form to ensure mating partners for offspring that will develop and mate within the syconia, or to dilute predation risk $^{10}$ as these wasps are constantly under attack by aggressive ants ${ }^{11}$. While an existing congregation of conspecifics can act as a direct visual cue to facilitate joining behaviour in a parasitoid, absence of conspecifics may require use of chemical cues to detect previous visits by conspecifics. In several insects, including non-parasitoid fig wasps, oviposition decisions are dictated by direct cues associated with the act of oviposition or indirect cues such as chemical footprints of conspecifics ${ }^{9,12-15}$. These different cues may be perceived by antennae and/or tarsal sensilla during host inspection ${ }^{16-18}$. We therefore studied the chemical footprints and tarsal morphology of fig wasp parasitoids.

Once the host presence is confirmed, hymenopteran parasitoids use their ovipositor not only as an egg-laying organ but also as a drilling device and a sensory organ ${ }^{19-21}$. In fig wasp parasitoids, the ovipositor is the only organ that makes physical contact with their insect hosts and wasps may rely on sequential and/or parallel processing of multiple cues to precisely locate hidden hosts. While species-specific cues such as volatiles and surface hydrocarbons provide reliability, non-specific cues such as carbon dioxide $\left(\mathrm{CO}_{2}\right)$ from respiring hosts may also act as context-specific cues ${ }^{22,23}$. There is also species-species variation in the size of galls induced by the hosts of fig wasp parasitoids ${ }^{24,25}$; galls are, therefore, expected to differ in their rate of respired $\mathrm{CO}_{2}$ emission. Since the ovipositors of Apocrypta respond behaviourally and electrophysiologically to $\mathrm{CO}_{2}$ (ref. 24), this inter-specific 

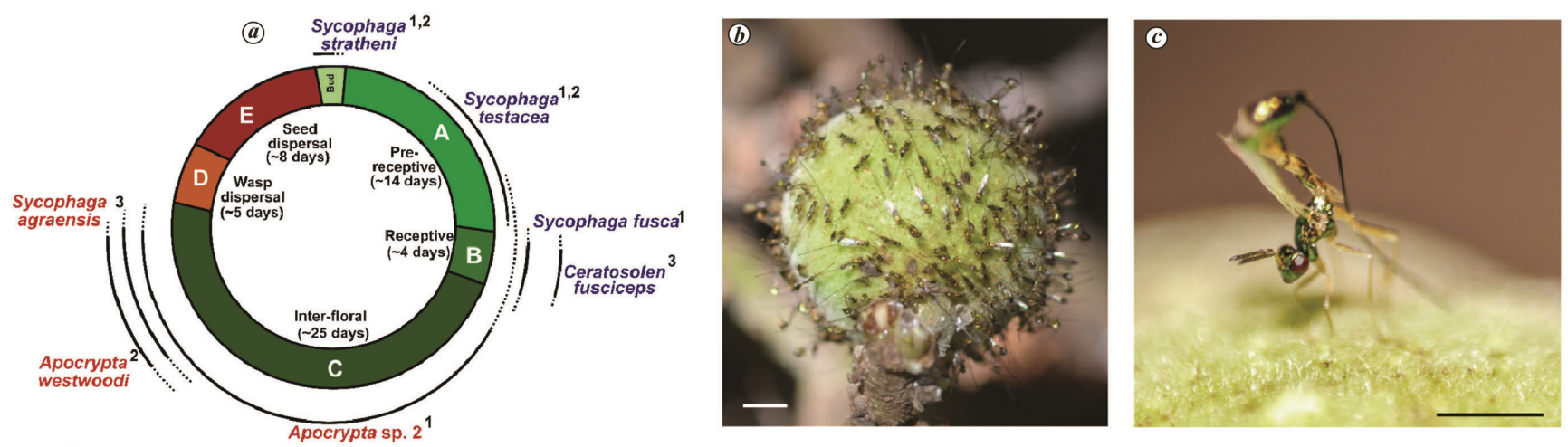

Figure 1. $\boldsymbol{a}$, Wasp arrival sequence for oviposition across syconium development phases (A-E) in Ficus racemosa (adapted from Ranganathan et $\left.a l .{ }^{28}\right)$. Solid lines represent top $50 \%$ of wasp arrival, while dotted lines represent the rest. Gallers are marked in blue and parasitoids in red. Numerical superscripts denote galler-parasitoid (host-parasite) pairs. $\boldsymbol{b}$, Apocrypta sp. 2 aggregations while ovipositing into a syconium (scale $=10$ mm). c, Single Apocrypta sp. 2 ovipositing (scale $=5 \mathrm{~mm}$; image courtesy: Nikhil More).

variation in $\mathrm{CO}_{2}$ production could act as a cue for host differentiation by parasitoids. We therefore characterized $\mathrm{CO}_{2}$ production of the galls of different fig wasp species that are hosts for parasitoids.

Host nutritional quality may also vary with host sex as reported in some phytophagous insects ${ }^{26}$; consequently, the host sex with appropriate nutritional value may be chosen. All fig wasp species (gallers and parasitoids) exhibit extreme sexual dimorphism and are haplodiploid; males and females associated with $F$. racemosa also differ in body mass with females weighing $0.22-1.14 \mathrm{mg}$ while males weigh about one-eighth of that at only $0.03-$ $0.19 \mathrm{mg}$ (ref. 27). There is therefore likely to be a sexassociated difference in nutritional requirements for a developing parasitoid and this difference is possibly reflected in parasitoid oviposition choice when depositing fertilized (female) or unfertilized (male) eggs on male or female hosts. We therefore asked the following questions:

(1) What is the chemical composition of footprints of Apocrypta sp 2 that may indicate, from outside the syconium, the presence of mates for offspring that will eclose within the syconium?

(2) What elements of tarsal morphology may aid surface chemical footprint recognition?

(3) Does respiratory rate (local $\mathrm{CO}_{2}$ levels around a gall in which prey is developing) vary between galls of different host species such that it may be used as proxy for prey size/identity?

(4) Do parasitoids exhibit a sex-based assortative preference for egg deposition?

\section{Materials and methods}

Study system: F. racemosa is pollinated by a specific agaonid wasp species, Ceratosolen fusciceps Mayr (Agaonidae $^{28}$ (Figure 1). The $F$. racemosa flowers are modified into galls by wasp oviposition and the larvae feed on galled tissue. $F$. racemosa syconia can also be occupied by six species of non-pollinating fig wasps (NPFWs) that oviposit into them from the exterior at different syconial developmental stages. These NPFWs are gallers - capable of modifying flowers into galls: Sycophaga stratheni Joseph, Sycophaga testacea Mayr, Sycophaga fusca Girault; or parasitoids - parasitisizing developing galler larvae: Sycophaga agraensis Joseph, Apocrypta sp. 2, Apocrypta westwoodi Grandi ${ }^{24,28}$ (Figure 1). Experiments were conducted with the most abundant parasitoid Apocrypta sp. 2. This species is an ectoparasitoid that parasitizes all three non-pollinating gallers during their larval stages (Figure 1) with specificity for early larval stages of $S$. testacea and $S$. stratheni and late larval stages of $S$. fusca $^{24}$. The taxonomists dealing with this group of parasitoids associated with $F$. racemosa throughout its Indo-Australasian range have named this taxon sp. 2 since there is already a species 1 which is Apocrypta westwoodi. Syconia and freshly enclosing parasitoid wasps, for all experiments, were collected between 1000 and $1200 \mathrm{~h}$.

\section{Outside the syconium: footprint chemical analysis and tarsal sensory morphology}

We collected and analysed footprints of the aggregating parasitoid Apocrypta sp. 2 following the method described in Yadav et al. ${ }^{15}$ for other fig wasps. Using gas chromatography-mass spectrometry (GC-MS) ( $n=6$ samples) we estimated the total quantity of identified compounds and calculated the proportional abundance of each compound. For examining tarsal sensory morphology, tarsi were excised from wasps in physiological saline and dehydrated. They were then gold sputter-coated at $10 \mathrm{~nm}$ and viewed in a FEI Quanta 200 ESEM scanning electron microscope at the Advanced Facility for Microscopy and Microanalysis (AFMM), Indian Institute of Science (IISc), Bengaluru, India. 
Inside the syconium: potential host location by parasitoids using respired $\mathrm{CO}_{2}$

$\mathrm{CO}_{2}$ emission values of species-specific galls at developmental stages relevant to the parasitoids, i.e. the early instar for all gallers as well as late instar for S. testacea ${ }^{24}$, were obtained using flow-through respirometry. A LICOR ${ }^{\mathrm{TM}}(\mathrm{Li}-820) \mathrm{CO}_{2}$ gas analyser was calibrated as described in Venkateswaran et al. ${ }^{29}$. The galls (collected by excising at the base of their pedicel) were placed in a perforated PCR vial (number of galls in the vial varied with species due to differences in gall size and fixed size of the vial). This vial was then placed inside the metabolic chamber for measurements lasting one hour. $\mathrm{CO}_{2}$ values were normalized per gall and expressed as ppm $\mathrm{CO}_{2} /$ gall. Sample size varied with species due to gall availability $(C$. fusciceps $=$ nine trials; $S$. strathen $i=$ nine; $S$. $\quad$ testacea $=$ eight (early second-third instar larval stage), three (late larval stage); $S$. fusca = four).

\section{Inside the syconium: sex-based assortative host selection by parasitoids}

Preference for sex of the host for oviposition: Three bunches, on two trees, bearing 10-15 fig syconia each were bagged, using cloth bags around a wire frame, during primordial stage to ensure no oviposition before the experiment. Unmated $S$. testacea galler females (10-15 females per bunch), capable of laying only unfertilized eggs and therefore producing only male offspring, were released into the bagged bunches. For collecting unmated S. testacea wasps, intact galls were dissected from nonexperimental fig syconia during late C-phase, the stage at which $S$. testacea enters pupation (Figure 1), and kept in laboratory conditions till they became adults and active ${ }^{24}$. Next, naturally eclosing Apocrypta sp. 2 females (assumed to be mated as they were collected outside galls that had been opened by males for mating) were collected, by letting females eclose in a closed container in the laboratory, from D-phase syconia and released into experimental bunches (10-15 females per bunch). Therefore, such parasitoids females were assumed to be able to lay eggs destined to become either male or female offspring. After $24 \mathrm{~h}$, they were removed and a fresh batch of mated Apocrytpa sp. 2 wasps was released. Parasitoid release was repeated daily for one week to ensure oviposition by fresh and naïve Apocrypta sp. 2 wasps, i.e. those with no prior ovipositions, to eliminate any possible effects of variation in egg-load and ageing on their oviposition choice $^{14}$. These bunches were then allowed to proceed with their development and syconia were collected in late C-phase, dissected open and the identity of wasps inside the galls induced by $S$. testacea was recorded. The experiment was repeated for three bunches per fig developmental cycle over four such cycles. Pollinators were not introduced into these syconia to prevent any confounding effects from non-host occupancy of the syconia; however, this meant that few syconia developed to maturity in the absence of pollinator development and thereby constrained final sample sizes.

\section{Results}

\section{Outside the syconium: footprint chemical analysis and tarsal sensory morphology}

The footprint extracts of Apocrypta sp. 2 tarsi consisted largely of a homologous series of saturated alkanes ranging from octacosane $\left(n-\mathrm{C}_{28}\right)$ to dotriacontane $\left(n-\mathrm{C}_{32}\right)$ with the monomethyl branched alkane 5-methyl hentriacontane $\left(5 \mathrm{MeC}_{31}\right)$ being the most abundant (Figure $2 a$ ). Some alkenes and alcohols were also present in minor quantities (Figure $2 a$ and $b$ ). The legs showed characteristic hymenopteran features with a basitarsal comb present on the foreleg and a tibial comb, claws and spur on all legs (Figure $3 a-c$ ). Some conical unidentified structures were also observed (Figure $3 a$ ). Additionally, SEM images revealed at least two different types of sensilla that morphologically appear to be sensilla chaetica and sensilla trichodea (Figure $3 a$ ), but need functional characterization.

\section{Inside the syconium: potential host location by parasitoids using respired $\mathrm{CO}_{2}$}

$\mathrm{CO}_{2}$ production by galls: The galls of different species released different amounts of $\mathrm{CO}_{2}$ (Kruskal-Wallis test, $\chi_{1}^{2}=26.37, P<0.001$; also significant for the dataset with total number of galls equalized between species or number of trials equalized per species). Sycophaga stratheni, with the largest galls ${ }^{25}$, had the highest $\mathrm{CO}_{2}$ output per gall (Figure 4). There were also differences between developmental stages of $S$. testacea and late larval instars producing more $\mathrm{CO}_{2}$ than early instars. Values for the late instar stage of $S$. stratheni could not be obtained due to its low abundance and high levels of parasitism by parasitoids.

\section{Inside the syconium: sex-based assortative host selection by parasitoids}

Preference for sex of the host during parasitoid oviposition: The high syconium abortion rate in the absence of pollinators resulted in an extremely low number of syconia that completed development (eight out of 280 bagged syconia over four cycles). Also, S. testacea usually induces low number of galls per syconia, possibly as a strategy to dilute the risk, over several syconia, of having its nursery aborted if pollination fails ${ }^{25}$. As a result, totally only 37 galls were induced by unmated $S$. testacea 


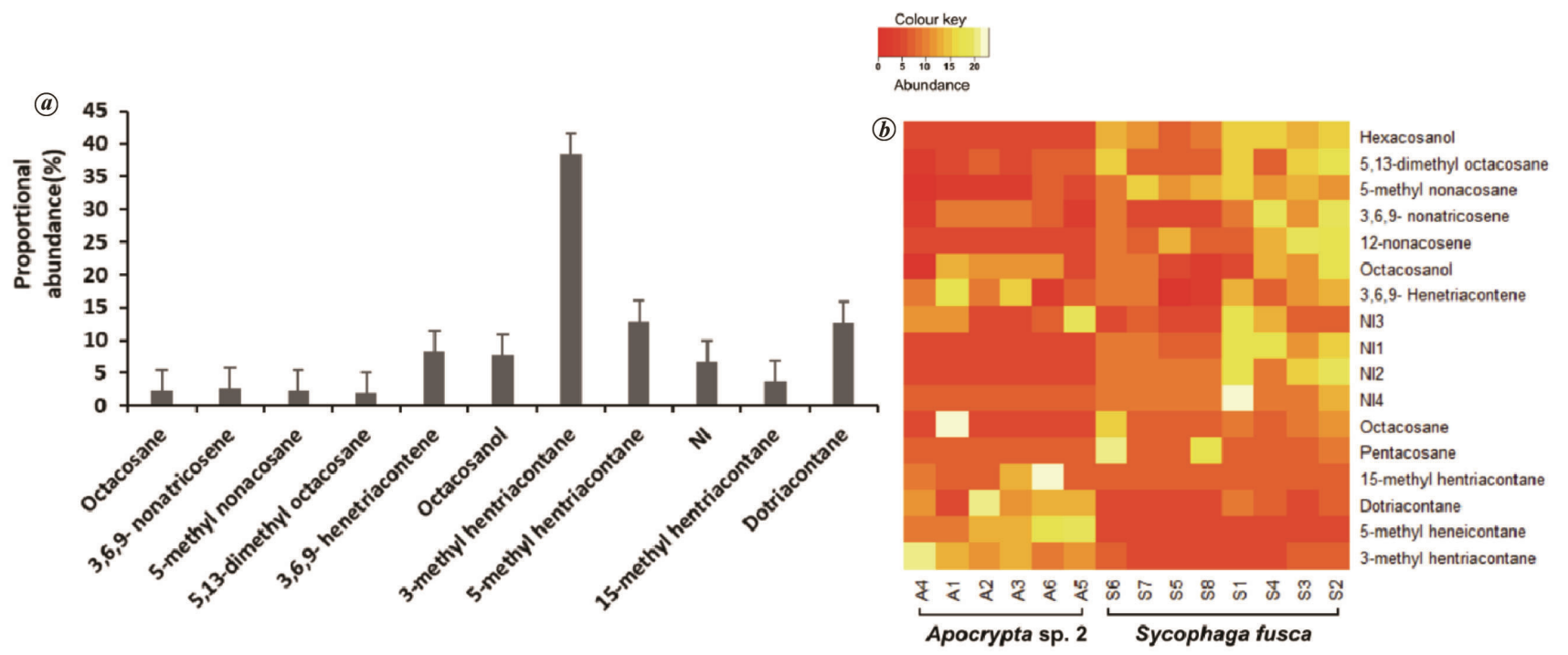

Figure 2. $\boldsymbol{a}$, Histogram showing proportional abundance of different compounds in footprint extracts of Apocrypta sp. 2 arranged by retention time. Error bars represent standard error $(n=6)$. NI, Not identified. $\boldsymbol{b}$, Heat map displaying proportional abundance of different compounds in footprint extracts of Apocrypta sp. 2 and Sycophaga fusca (data for S. fusca from Yadav and Borges ${ }^{24}$ ). A1-A6 denote Apocrypta sp. 2 samples and S1-S8 represent $S$. fusca samples. (Colour key denotes abundance in colour gradient units.)
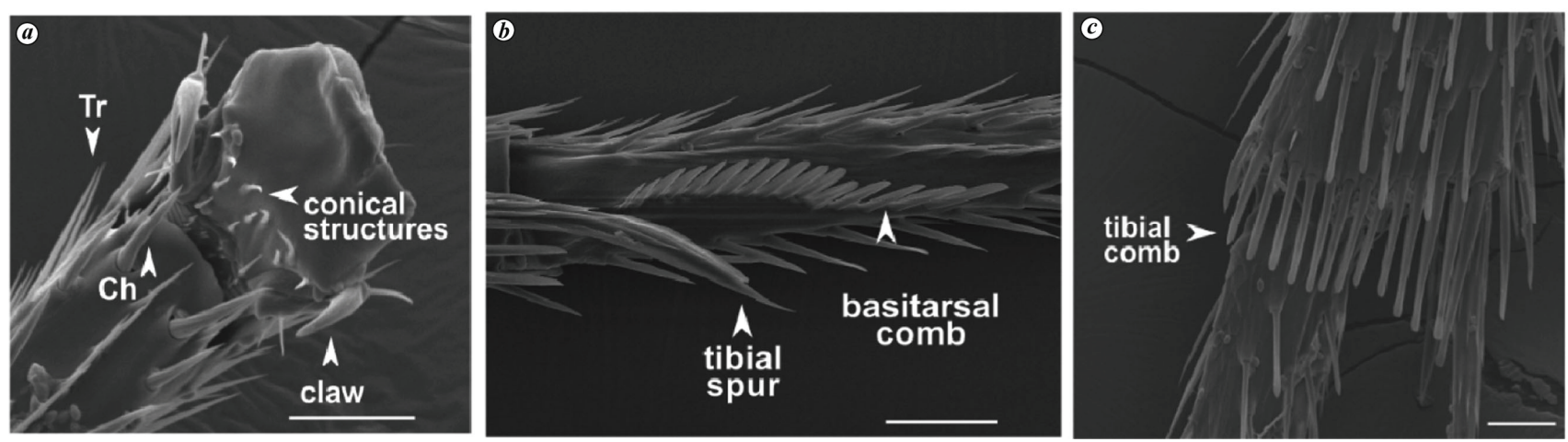

Figure 3. SEM photomicrographs of Apocrypta sp. 2 tarsi: $(\boldsymbol{a}, \boldsymbol{b})$ foreleg and $(\boldsymbol{c})$ hind leg showing tibial and tarsal combs. Scale: $25 \mu \mathrm{m}$. Tr, Sensilla trichodea; Ch, Sensilla chaetica.

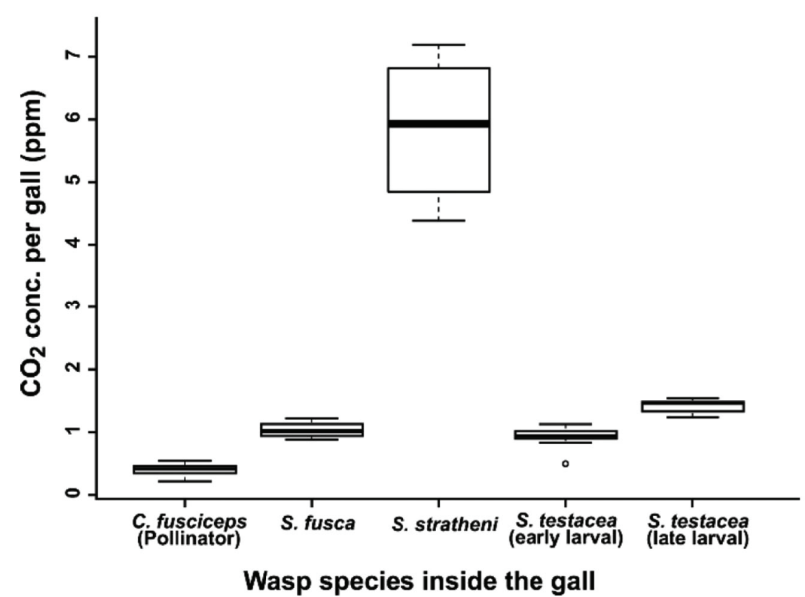

Figure 4. Carbon dioxide concentration of galls of four fig wasp species measured at the developmental stage of parasitoid exploitation. The first four box-plots represent different species at early larval stage and the last two box-plots represent $S$. testacea galls at early and late larval stages. females in eight syconia over four cycles. No galler females (S. testacea) were found developing inside the galls (supporting the fact that the introduced galler females were unmated). Only galler males were present in unparasitized galls ( $n=10$ galls) and only parasitoid males were found in parasitized galls $(n=27$ galls). This suggests sex-biased assortative oviposition in that parasitoid females lay their unfertilized eggs (males) in male hosts.

\section{Discussion}

What is the chemical composition of footprints of Apocrypta sp. 2 that may indicate, from outside the syconium, the presence of mates for offspring?

In ovipositing females, the decision to join (or avoid) a previously exploited resource can have significant fitness consequences ${ }^{9}$. In non-pollinating fig wasps such as 
Apocrypta sp. 2, mating between offspring of ovipositing females takes place only within the natal syconium ${ }^{30}$. Thus, conspecific footprints on syconia may indicate prior visits by ovipositing females and thereby decrease inbreeding by increasing the probability of finding mates that are non-siblings for future parasitoid offspring. While attraction to syconia previously visited by conspecifics has been observed in gallers such as $S$. fusca wasps in laboratory settings ${ }^{14,15}$, it is extremely hard to perform a similar experiment with parasitoids because it is difficult to guarantee the presence of galler hosts and developing conspecifics inside a syconium. However, since both non-pollinating gallers and parasitoids have similar challenges with respect to sib-mating inside a syconia and both exhibit aggregation on syconia for oviposition, we expect parasitoids to prefer syconia with previous oviposition by conspecifics. All these behavioural responses rely on identifying conspecific signatures as well as distinguishing them from heterospecific signatures that may be present on the fig syconium surface, both of which require species-specific chemical footprints ${ }^{31,32}$. Cuticular hydrocarbons (CHCs) in the range of $\mathrm{C} 25-\mathrm{C} 32$ are ubiquitously present in the chemical footprint profile of several insect species; however, it is the variation in proportional abundance of different constituents that gives them their unique identity and their chemically stable structure lends them reliability $8,33,34$. The footprint extract of Apocrypta sp. 2 was found to be substantially different from its host, galler $S$. fusca, that arrives for oviposition into $F$. racemosa syconia around the same time ${ }^{15}$ forming two distinct clusters in the heat map (Figure $2 b$ ). The CHC 3-methyl hentriacontane is present in high abundance in Apocrypta sp. $2(\sim 38 \%)$ compared to S. fusca $(10 \%)$ and is a possible signature compound for Apocrypta sp. 2, whereas the putative signature compound of $S$. fusca, 5-methyl nonacosane (33\% abundance), had low abundance in Apocrypta sp. 2 (2.3\%). Additionally, the two species differ in a total of 16 compounds that were present in low abundance. The distinctive footprint signature of two wasps that oviposit at the same time from the exterior of the fig syconium can likely prevent signal confusion $^{31,35}$. These chemical signatures are generally perceived by antennation as well as sensilla present on the tarsal pads of insects ${ }^{36,37}$. It is possible that Apocrypta sp. 2 can also recognize the footprints of $S$. fusca that may reaffirm the presence of oviposition by one of its hosts (S. fusca) in the syconium. Therefore, footprint recognition may provide two messages, one pertaining to conspecific oviposition and the other to host presence within the syconium.

\section{What elements of tarsal morphology may aid surface chemical footprint recognition?}

Of the two sensilla types observed in Apocrypta sp. 2 tarsi, sensilla chaetica could be involved in mechanoreception or both chemo- and mechanoreception, whereas sensilla trichodea is likely purely chemosensory in nature ${ }^{38,39}$. Apocrypta sp. 2 also grooms the ovipositor using its tibia prior to its insertion into the syconium (pers. obs.; Figures $1 c$ and $3 c$ ); the tibial comb in this case is similar to that used for antennal grooming ${ }^{40,41}$. We surmise that, in fig wasp parasitoids, the hind leg tibial combs could be primarily used for grooming the ovipositor which, for a parasitoid that uses its ovipositor to find hidden hosts, is as vital in host location as its antennae. Prevention of grooming of antennae results in the loss of olfactory acuity $^{42}$. This loss may be equally applicable to an ovipositor that needs to maintain sensitivity given its few sensilla $^{21,23}$, making ovipositor grooming using the tibial comb also an important activity.

\section{Does respiratory rate (local $\mathrm{CO}_{2}$ levels around a gall in which prey is developing) vary between galls of different host species such that it may be used as a proxy for prey size/identity?}

The observed respired $\mathrm{CO}_{2}$ variation can be attributed to the difference in gall size which in turn depends on the size of the developing species ${ }^{24,25}$. Species of similar size, i.e. the pollinator and $S$. fusca induce similar-sized galls ${ }^{25}$ which emit similar amounts of $\mathrm{CO}_{2}$ whereas larger galls, induced by $S$. stratheni and housing larger larvae emit higher amounts of $\mathrm{CO}_{2}$. The parasitoid ovipositor is a $\mathrm{CO}_{2}$ and volatile sensor ${ }^{23}$, supporting our hypothesis that parasitoid wasps use $\mathrm{CO}_{2}$ as a cue to differentiate between host species and/or the developmental stage of host larvae ${ }^{24}$. However, $\mathrm{CO}_{2}$ is a context-specific cue ${ }^{22}$ and may provide only size-based differentiation of hosts. Preliminary trials with litmus paper (results not shown) using slices of fig syconia showed clear zones of acidic $\mathrm{pH}$ rich in carbonate ions around galls surrounded by zones of low carbonate ions, indicating that the inside of the fig syconium presents a mixture of 'hot' and 'cold' spots of $\mathrm{CO}_{2}$ concentration to a discerning parasitoid ovipositor. However, in order to differentiate precisely, especially between species with similar gall size, we expect parasitoids to rely on additional chemical cues such as gall surface hydrocarbons since the pollinator, whose galls emit that same amount of $\mathrm{CO}_{2}$ as $S$. fusca, is not a host for Apocrypta sp 2. Data on gall surface hydrocarbons are not yet available, although the CHCs of each fig wasp species in this system, including those of males and females are distinct ${ }^{43}$.

\section{Do parasitoids exhibit a sex-based assortative preference for egg deposition?}

Variation in the nutritional value of the hosts may depend not only on the species or the developmental stage of the host, i.e. larva vs pupa, but also its $\operatorname{sex}^{44,45}$. In the fig-fig 


\section{RESEARCH ARTICLES}

wasp system, wingless galler males (as well as parasitoid males) have a short lifespan of $\sim 1-2$ days ${ }^{27,30}$. Galler females, on the other hand, live for much longer $(\sim 10-12$ days), carry eggs and fly in search of host syconia ${ }^{27,30}$. Given that these gallers are capital breeders ${ }^{27}$ and rely solely on resource capital that they have stored during development since they do not feed during their short lifespan, females need to acquire significantly higher resources during their development in order to survive and reproduce. Conversely, developing male gallers would acquire less resources and are likely to be nutritionally poorer hosts, than female gallers, for parasitoids. Also, since the wingless male parasitoids have a lifespan and activity similar to wingless galler males ${ }^{27}$, parasitoids would benefit by utilizing male hosts for laying only unfertilized (male) eggs, which is corroborated by our results. This provides indirect support to the hypothesis that female eggs are only laid in female hosts owing to higher nutrition availability, although this could not be unequivocally tested due to the impossibility of obtaining females with only fertilized eggs. Since no empty galls were found, we rule out the possibility that female embryos developed on the host within the gall but died prior to maturity. Although researchers have focused on resource acquisition and allocation differences between sexes, its implication for parasitoid oviposition choices has not been earlier addressed ${ }^{45,46}$. To the best of our knowledge, no previous studies have explored this aspect of host preference in parasitoids and leads to questions on the mechanism of male-female host differentiation in parasitoids, which need future research.

This study explored different aspects of host location behaviour in parasitoids, including a hitherto unexplored aspect, i.e. host sex preference. The complexity of the fig system presents the possibility of several other yet unexplored phenomena, such as vibrational cues from host larvae and the role of hetero-specific parasitoid cues in oviposition decisions that remain to be examined.

1. Godfray, H. C. J. and Shimada, M., Parasitoids as model organisms for ecologists. Res. Popul. Ecol., 1999, 41, 3-10.

2. Mills, N. J. and Wajnberg, E., Optimal foraging behaviour and efficient biological control. In Behavioral Ecology of Insect Parasitoids from Theoretical Approaches to Field Applications (eds Wajnberg, E., Bernstein, C. and van Alphen, J. J. M.), Blackwell Science, Oxford, 2008, pp. 3-30.

3. van Oudenhove, L., Mailleret, L. and Fauvergue, X., Infochemical use and dietary specialization in parasitoids: a meta-analysis. Ecol. Evol., 2017, 7, 4804-4811.

4. Dicke, M., Vet, L. E. and Wäckers, F. L., How to hunt for hiding hosts: the reliability-detectability problem in foraging parasitoids. Neth. J. Zool., 1990, 41, 202-213.

5. Chhan, S. and Morse, D. H., To mate or not to mate, and subsequent host search by a haplodiploid female parasitoid wasp. Ethology, 2019, 125, 457-464.

6. Krimmel, B. A. and Morse, D. H., Host-size decisions of female parasitoid wasps seeking hidden hosts. Ecol. Entomol., 2019, 44, $552-559$.
7. Borges, M., Colazza, S., Ramirez-Lucas, P., Chauhan, K. R., Moraes, M. C. B. and Richard Aldrich, J., Kairomonal effect of walking traces from Euschistus heros (Heteroptera: Pentatomidae) on two strains of Telenomus podisi (Hymenoptera: Scelionidae). Physiol. Entomol., 2003, 28, 349-355.

8. Rostás, M. and Wölfling, M., Caterpillar footprints as host location kairomones for Cotesia marginiventris: persistence and chemical nature. J. Chem. Ecol., 2009, 35, 20-27.

9. Prokopy, R. J. and Roitberg, B. D., Joining and avoidance behavior in nonsocial insects. Annu. Rev. Entomol., 2001, 46, 631-665.

10. Dittmann, L. and Schausberger, P., Adaptive aggregation by spider mites under predation risk. Sci. Rep., 2017, 7, 10609.

11. Ranganathan, Y. and Borges, R. M., Predatory and trophobionttending ants respond differently to fig and fig wasp volatiles. Anim. Behav., 2009, 77, 1539-1545.

12. Saleh, N. and Chittka, L., The importance of experience in the interpretation of conspecific chemical signals. Behav. Ecol. Sociobiol., 2006, 61, 215-220.

13. Wheeler, C. A. and Cardé, R. T., Following in their footprints: cuticular hydrocarbons as overwintering aggregation site markers in Hippodamia convergens. J. Chem. Ecol., 2014, 40, 418-428.

14. Yadav, P. and Borges, R. M., Why resource history matters: age and oviposition history affect oviposition behaviour in exploiters of a mutualism. Ecol. Entomol., 2018, 43, 473-482.

15. Yadav, P., Desireddy, S., Kasinathan, S., Bessière, J. M. and Borges, R. M., History matters: Oviposition resource acceptance in an exploiter of a nursery pollination mutualism. J. Chem. Ecol., $2018,44,18-28$.

16. van Baaren, J., Boivin, G., Bourdais, D. and Roux, O., Antennal sensilla of hymenopteran parasitic wasps: variations linked to host exploitation behaviour. In Modern Research and Educational Topics in Microscopy (eds Méndez-Vilas, A. and Díaz, J.), Formatex, Badajoz, Spain, 2007, pp. 345-352.

17. Ma, L., Li, Z. Q., Bian, L., Cai, X. M., Luo, Z. X., Zhang, Y. J. and Chen, Z. M., Identification and comparative study of chemosensory genes related to host selection by legs transcriptome analysis in the tea geometrid Ectropis obliqua. PLoS ONE, 2016, 11, e0149591.

18. Sollai, G., Biolchini, M., Loy, F., Solari, P. and Crnjar, R., Taste input from tarsal sensilla is related to egg-laying behavior in Papilio hospiton. Entomol. Exp. Appl., 2017, 165, 38-49.

19. Quicke, D. L. J., LeRalec, A. and Vilhelmsen, L., Ovipositor structure and function in the parasitic Hymenoptera with an exploration of new hypotheses. Rendiconti, 1999, 47, 197-239.

20. Cerkvenik, U., van de Straat, B., Gussekloo, S. W. and van Leeuwen, J. L., Mechanisms of ovipositor insertion and steering of a parasitic wasp. Proc. Natl. Acad. Sci. USA, 2017, 114, 7822-7831.

21. Ghara, M., Kundanati, L. and Borges, R. M., Nature's Swiss army knives: ovipositor structure mirrors ecology in a multitrophic fig wasp community. PLoS ONE, 2011, 6, e23642.

22. Goyret, J., Markwell, P. M. and Raguso, R.A., Context- and scale dependent effects of floral $\mathrm{CO}_{2}$ on nectar foraging by Manduca sexta. Proc. Natl. Acad. Sci. USA, 2008, 105, 4565-4570.

23. Yadav, P. and Borges, R. M., The insect ovipositor as a volatile sensor within a closed microcosm. J. Exp. Biol., 2017, 220, 15541557.

24. Yadav, P. and Borges, R. M., Host-parasitoid development and survival strategies in a non-pollinating fig wasp community. Acta Oecol., 2018, 90, 60-68.

25. Ghara, M., Ranganathan, Y., Krishnan, A., Gowda, V. and Borges, R. M., Divvying up an incubator: how parasitic and mutualistic fig wasps use space within their nursery microcosm. Arthropod Plant Interact, 2014, 8, 191-203.

26. Telang, A., Booton, V., Chapman, R. F. and Wheeler, D. E., How female caterpillars accumulate their nutrient reserves. J. Insect Physiol., 2001, 47, 1055-1064. 
27. Ghara, M. and Borges, R. M., Comparative life-history traits in a fig wasp community: implications for community structure. Ecol. Entomol., 2010, 35, 139-148.

28. Ranganathan, Y., Ghara, M. and Borges, R. M., Temporal associations in fig-wasp-ant interactions: diel and phenological patterns. Entomol. Exp. Appl., 2010, 137, 50-61.

29. Venkateswaran, V., Shrivastava, A., Kumble, A. L. and Borges, R. M., Life-history strategy, resource dispersion and phylogenetic associations shape dispersal of a fig wasp community. Mov. Ecol., $2017, \mathbf{5}, 25$.

30. Weiblen, G. D., How to be a fig wasp. Annu. Rev. Entomol., 2002, 47, 299-330.

31. Conti, E., Salerno, G., Bin, F. and Vinson, S. B., The role of host semiochemicals in parasitoid specificity: a case study with Trissolcus brochymenae and Trissolcus simoni on pentatomid bugs. Biol. Control, 2004, 29, 435-444.

32. Fatouros, N. E., Dicke, M., Mumm, R., Meiners, T. and Hilker, M., Foraging behavior of egg parasitoids exploiting chemical information. Behav. Ecol., 2008, 19, 677-689.

33. Martin, S. J., Helanterä, H. and Drijfhout, F. P., Colony-specific hydrocarbons identify nest mates in two species of Formica ant. J. Chem. Ecol., 2008, 34, 1072-1080.

34. Curtis, S., Sztepanacz, J. L., White, B. E., Dyer, K. A., Rundle, H. D. and Mayer, P., Epicuticular compounds of Drosophila subquinaria and $D$. recens: identification, quantification, and their role in female mate choice. J. Chem. Ecol., 2013, 39, 579-590.

35. Peri, E., Frati, F., Salerno, G., Conti, E. and Colazza, S., Host chemical footprints induce host sex discrimination ability in egg parasitoids. PLoS ONE, 2013, 8, e79054.

36. Ozaki, M. et al., Ant nestmate and non-nestmate discrimination by a chemosensory sensillum. Science, 2005, 309, 311-314.

37. Chen, Y. and Amrein, H., Enhancing perception of contaminated food through acid-mediated modulation of taste neuron responses. Curr. Biol., 2014, 24, 1969-1977.

38. Maher, N. and Thiery, D., Distribution of chemo- and mechanoreceptors on the tarsi and ovipositor of female European grapevine moth, Lobesia botrana. Entomol. Exp. Appl., 2004, 110, 135-143.
39. Loy, F., Solari, P., Isola, M., Crnjar, R. and Masala, C., Morphological and electrophysiological analysis of tarsal sensilla in the medfly Ceratitis capitata (Wiedemann, 1824) (Diptera: Tephritidae). Ital. J. Zool., 2016, 83, 456468.

40. Walker, E. D. and Archer, W. E., Sequential organization of grooming behaviors of the mosquito, Aedes triseriatus. J. Insect Behav., 1988, 1, 97-109.

41. Rebora, M., Salerno, G., Piersanti, S., Michels, J. and Gorb, S., Structure and biomechanics of the antennal grooming mechanism in the southern green stink bug Nezara viridula. J. Insect Physiol., 2019, 112, 57-67.

42. Böröczky, K., Wada-Katsumata, A., Batchelor, D., Zhukovskaya, M. and Schal, C., Insects groom their antennae to enhance olfactory acuity. Proc. Natl. Acad. Sci. USA, 2013, 110, 3615-3620.

43. Ranganathan, Y., Bessiere, J. M. and Borges, R. M., A coat of many scents: cuticular hydrocarbons in multitrophic interactions of fig wasps with ants. Acta Oecol., 2015, 67, 24-33.

44. Scriber, J. M. and Slansky Jr, F., The nutritional ecology of immature insects. Annu. Rev. Entomol., 1981, 26, 183211.

45. Lease, H. M. and Wolf, B. O., Lipid content of terrestrial arthropods in relation to body size, phylogeny, ontogeny and sex. Physiol. Entomol., 2011, 36, 29-38.

46. Lee, K. P., Sex-specific differences in nutrient regulation in a capital breeding caterpillar, Spodoptera litura (Fabricius). $J$. Insect Physiol., 2010, 56, 1685-1695.

ACKNOWLEDGEMENTS. This work was funded by the Ministry of Environment and Forests, Government of India. It also utilized funds from the Department of Biotechnology (DBT), New Delhi; DBT-IISc Partnership Programme; Department of Science and Technology (DST), New Delhi and DST-FIST.

Received 10 March 2021; accepted 11 May 2021

doi: $10.18520 / \mathrm{cs} / \mathrm{v} 121 / \mathrm{i} 1 / 141-147$ 